\title{
High-dose chemotherapy combined with autologous peripheral blood stem cell transplantation in children with advanced malignant solid tumors: A retrospective analysis of 38 cases
}

\author{
WEI-LING ZHANG ${ }^{1 *}$, YI ZHANG ${ }^{2 *}$, TIAN ZHI ${ }^{1}$, DONG-SHENG HUANG ${ }^{1}$, YI-ZHUO WANG ${ }^{1}$, \\ LIANG HONG ${ }^{1}$, XIA ZHU ${ }^{1}$, AI-PING LIU ${ }^{1}$ and HUI-MIN HU ${ }^{1}$ \\ ${ }^{1}$ Department of Pediatrics, Beijing Tongren Hospital, Capital Medical University, Beijing 100176; \\ ${ }^{2}$ Department of Pediatrics, Chinese PLA General Hospital, Beijing 100853, P.R. China
}

Received April 30, 2014; Accepted January 16, 2015

DOI: $10.3892 / 01.2015 .3272$

\begin{abstract}
The aim of the present study was to assess the toxicity and efficacy of autologous peripheral blood stem cell (APBSC) transplantation in children with advanced malignant solid tumors. The outcomes of 38 children with advanced malignant solid tumor, who were treated with high-dose chemotherapy and autologous peripheral blood stem cell transplantation in Beijing Tongren Hospital (Capital Medical University, Beijing, China) between September 2005 and November 2011, were retrospectively analyzed. The effects of treatment were evaluated according to the standard Bearman's criteria. The mean count of collected mononuclear cells and the cluster of differentiation $34^{+}$cell count from 38 patients was $5.6 \pm 2.2 \times 10^{8} / \mathrm{kg}$ and $3.8 \pm 2.6 \times 10^{6} / \mathrm{kg}$, respectively. From these 38 patients, the number of stem cells collected from 31 cases $(81.6 \%)$ accorded with the transplantation standards. Three and 14 days after pretreatment in these 38 cases, there were 19 cases of grade I, 11 cases of grade II, five cases of grade III and three cases of grade IV (one case succumbed) adverse reaction. Following the treatment (23-40 days after pretreatment, during organ injury recovery), 37 cases obtained bone marrow reconstitution with a mean time of 12.3 \pm 3.1 days after APBSC reinfusion. The median survival time of the 37 patients was 49 months, and the survival rate at one, three and five years post-treatment was 91.9, 68.2 and $36.6 \%$, respectively.
\end{abstract}

Correspondence to: Professor Dong-Sheng Huang, Department of Pediatrics, Beijing Tongren Hospital, Capital Medical University, 8 Chongwenmen Street, Dongcheng, Beijing 100176, P.R. China E-mail: huangdongsheng99@163.com

*Contributed equally

Key words: autologous, peripheral blood stem cell, transplantation, solid tumor, children

\section{Introduction}

Advanced malignant solid tumors in children have the characteristics of a short incubation period, extensive metastasis and rapid growth, and are the second leading cause of cancer-related mortality in children. Thus, advanced malignant solid tumors are of serious threat to the health of children worldwide (1-3). Peripheral blood stem cell transplantation (PBSCT) is the most common transplantation procedure performed in medicine; autologous PBSCs are the most common source of stem cells used in the autologous transplantation setting (4). PBSCs have previously been shown to be capable of supporting rapid and complete hematopoietic reconstitution when used for autologous transplantation (5-7). Recently, autologous PBSCT (APBSCT) has begun to replace autologous bone marrow transplantation due to its rapid rate of engraftment and low transplant-related mortality (8-11).

However, children with advanced malignant solid tumors are usually of low weight, with a young age of onset $(12,13)$, thin venous access and a low total blood volume, which makes it difficult to control the dosage of anticoagulant drug and the side-effects of reinfusion or post-reinfusion. These factors all increase the risk of the recruitment, collection and reinfusion process of APBSC in children with solid tumors $(14,15)$. The present study reports the outcomes of 38 children with advanced malignant solid tumors who received high-dose chemotherapy (HDCT) and APBSCT treatment between September 2005 and November 2011 in Beijing Tongren Hospital (Capital Medical University, Beijing, China).

\section{Patients and methods}

Patients. The study was approved by the Ethics Committee of Beijing Tongren Hospital, and was conducted in accordance with the Declaration of Helsinki. Written informed consent was obtained from all subjects or their parents. A total of 38 patients with advanced malignant solid tumors were recruited between September 2005 and November 2011. The 38 patients consisted of 27 males and 11 females, with a median age of 6.4 years (range, 1-14 years). The median weight was $22.3 \mathrm{~kg}$ (range, $11-75 \mathrm{~kg}$ ). The distribution of 
Table I. Pre-transplant conditions of 38 children patients who received autologous peripheral blood stem cell transplantation.

\begin{tabular}{|c|c|c|c|c|c|c|c|c|}
\hline \multirow[b]{2}{*}{ Groups } & \multirow[b]{2}{*}{ Cases, $\mathrm{n}$} & \multicolumn{3}{|c|}{ Patient condition, $\mathrm{n}$} & \multicolumn{2}{|c|}{ Gender, $\mathrm{n}$} & \multirow{2}{*}{$\begin{array}{l}\text { Age, years } \\
\text { (range) }\end{array}$} & \multirow{2}{*}{$\begin{array}{l}\text { Number of chemo- } \\
\text { therapy courses prior to } \\
\text { transplantation, } n\end{array}$} \\
\hline & & $\mathrm{CR}$ & PR & $\mathrm{DP}$ & M & $\mathrm{F}$ & & \\
\hline NB & 24 & 11 & 6 & 7 & 17 & & $6.22 \pm 3.09^{a}(1.5-14)$ & $3.76 \pm 2.45^{\mathrm{a}}$ \\
\hline PNET & 2 & 2 & & & 1 & 17 & $6.00 \pm 3.00^{\mathrm{a}}(3-9)$ & $7.00 \pm 1.00^{\mathrm{a}}$ \\
\hline $\mathrm{RB}$ & 5 & 2 & 2 & 1 & 1 & 4 & $3.42 \pm 2.06^{\mathrm{a}}(1-6)$ & $9.8 \pm 4.3^{\mathrm{a}}$ \\
\hline RMS & 4 & & 4 & & 3 & 1 & $8.75 \pm 4.57^{\mathrm{a}}(3-14)$ & $7.25 \pm 2.62^{\mathrm{a}}$ \\
\hline HP & 1 & & & 1 & 1 & & 11 & 65 \\
\hline MSN & 1 & & & 1 & & 1 & 10 & 45 \\
\hline Wilms & 1 & & 1 & & 1 & & 10 & 61 \\
\hline Total & 38 & 14 & 14 & 10 & 23 & 15 & $6.3 \pm 3.4^{\mathrm{a}}$ & \\
\hline
\end{tabular}

a Data expressed as the mean \pm SD. SD, standard deviation; NB, neuroblastoma; RB, retinoblastoma; RMS, rhabdomysarcoma; PNET, primitive neuroectodermal tumor.

tumor types was as follows: Neuroblastoma (NB) in 24 cases, retinoblastoma in five cases, rhabdomysarcoma in four cases, primitive neuroectodermal tumor in two cases, hepatoblastoma in one case, Wilms' tumor in one case and malignant schwannoma in one case. The pre-transplant conditions were ranked as complete remission (CR), partial remission (PR) and progressive disease (PD). The patient characteristics are summarized in Table I.

Chemotherapy and PBSC collection. Pre-operatively, 6-61 cycles of induction chemotherapy were administered to all children. Following initial conventional chemotherapy, a physical examination and laboratory tests were performed. Hematopoietic progenitor cells were mobilized by chemotherapeutic treatment followed by administration of $5-10 \mu \mathrm{g} / \mathrm{kg}$ subcutaneous granulocyte colony-stimulating factor (G-CSF) daily (Filgrastim; Amgen, Inc., Thousand Oaks, CA, USA) until the level of peripheral white blood cells (WBCs) had decreased to $2 \times 10^{9} / 1$ (16). The detailed mobilization programs and drugs used are listed in Table II.

The collection of the APBSCs was performed when the WBC count was $>5 \times 10^{9} / 1$, using a continuous flow blood cell separator (CS-3000; Baxter, Deerfield, IL, USA). In this series of patients, small volume collection chamber (SVCC) separation and a groove clamp were used for patients weighing $\leq 20 \mathrm{~kg}$. In all patients, the extracorporeal line was primed with $400 \mathrm{ml}$ of leukocyte-depleted red blood cells following regular priming with normal saline. In Beijing Tongren Hospital, all patients who weigh $<30 \mathrm{~kg}$ automatically undergo this optional procedure. Prior to collection, patients were required to take two pills of calcium carbonate $(600 \mathrm{mg})$, daily for two days. During the collection procedure, acid-citrate-dextrose was used as an anticoagulant in a ratio of 1:10 to $1: 13 \mathrm{ml}$ of whole blood, and calcium gluconate $(5 \mathrm{ml} / 1,500 \mathrm{ml}$ of processed blood) was administered continuously during apheresis to prevent hypocalcemia. No other drugs were used and the patients were not sedated during the procedure. A mononuclear cell (MNC) count of $>5 \times 10^{8} / \mathrm{kg}$ or a cluster of differentiation (CD) $34^{+}$cell count of $>3 \times 10^{6} / \mathrm{kg}$ was used as the harvest criterion. At $6 \mathrm{~h}$ after the start of collection, the number of platelets (PLTs) had to be $\geq 5.0 \times 10^{-10} / 1$, otherwise $1-2$ units of PLT was infused into these patients. The harvested PBSCs were stored frozen at $-196^{\circ} \mathrm{C}$.

APBSCT. The pre-transplant pretreatment regimen consisted of high-dose aclacinomycin, cyclophosphamide, cisplatin, carboplatin, dactinomycin, daunorubicin, etoposide, ifosfamide, paclitaxel, teniposide and vincristine. The detailed data is summarized in Table II. In addition, oral non-absorbed antibiotics (compound sulfamethoxazole tablets, $50 \mathrm{mg} / \mathrm{kg}$, once) were administered to prevent infection, and complementary medicine (0.6-1.2 g reduced glutathione, once and 5-10 ml polyene phosphatidylcholine, once) was administered intravenously to protect the liver, the myocardium and the gastrointestinal mucosa. Prior to reinfusion, antihistamines (5-10 mg loratadine, for 1-3 days) and intravenous hormone drugs $(2 \mathrm{mg} / \mathrm{kg}$ methylprednisolone, every $12 \mathrm{~h}$, for $1-3$ days $)$ were administered to all patients. On the 8th and 9th day of pretreatment, cryopreserved PBSCs were rapidly thawed in a $39^{\circ} \mathrm{C}$ water bath and infused through a central venous catheter without washing. During the whole reinfusion process, the patient's vital signs were observed.

After day 1 of transplantation, recombinant human G-CSF (rhG-CSF) was administered intravenously at a dose of $5-10 \mu \mathrm{g} / \mathrm{kg}$ on each day ( +1 day). Engraftment was confirmed by recovery of peripheral $\mathrm{WBC}$ counts to $>2 \times 10^{9} / 1$, a granulocyte count of $>0.5 \times 10^{9} / 1$, an absolute neutrophil count of $>0.5 \times 10^{9} / 1$, a hemoglobin concentration of $>80 \mathrm{~g} / 1$ and a PLT count of $>20 \times 10^{9} / 1$, without dependence on PLT transfusion for three consecutive days.

Medical evaluation and follow-up. The observed indicators during APBSC collection included heart rate, breathing rate, blood oxygen level, blood pressure value and other adverse reactions, such as paleness, sweating, nausea, vomiting, numbness and chills.

The adverse reactions during reinfusion were as follows: Abnormal heart rate, breathing, blood oxygen, blood pressure, and heart, liver and renal function indicators, and other adverse reactions, such as hemoglobinuria, headache, nausea, vomiting and diarrhea. 
Table II. Mobilization program and pretreatment treatment regimens for 38 children with advanced malignant solid tumor.

\begin{tabular}{|c|c|c|c|c|}
\hline Diagnosis & High-dose therapy & Medication & Cases & Ratio, $\%$ \\
\hline \multirow[t]{4}{*}{ Neuroblastoma } & $\mathrm{CDV}$ & $\begin{array}{l}\text { Cy, } 2.1 \mathrm{~g} / \mathrm{m}^{2} / \text { day, days } 1-2 \\
\mathrm{D}, 25 \mathrm{mg} / \mathrm{m}^{2} / \text { day, days } 1-3 \\
\mathrm{~V}, 0.67 \mathrm{mg} / \mathrm{m}^{2} / \text { day, days } 1-3\end{array}$ & 17 & 70.8 \\
\hline & $\mathrm{CiE}$ & $\begin{array}{l}\mathrm{Ci}, 50 \mathrm{mg} / \mathrm{m}^{2} / \text { day, days } 1-4 \\
\mathrm{E}, 200 \mathrm{mg} / \mathrm{m}^{2} / \text { day, days } 1-3\end{array}$ & 3 & 12.5 \\
\hline & CHOP & $\begin{array}{l}\text { Cy, } 1 \mathrm{~g} / \mathrm{m}^{2} / \text { day, days } 1-3 \\
\mathrm{~V}, 1.5 \mathrm{mg} / \mathrm{m}^{2} / \text { day, day } 1 \\
\mathrm{~A}, 25 \mathrm{mg} / \mathrm{m}^{2} / \text { day, days } 1-2 \\
\mathrm{P}, 100 \mathrm{mg} / \mathrm{m}^{2} / \text { day, days } 1-5\end{array}$ & 3 & 12.5 \\
\hline & IT & $\begin{array}{l}\mathrm{I}, 2 \mathrm{~g} / \mathrm{m}^{2} / \text { day, days } 1-5 \\
\mathrm{~T}, 100 \mathrm{mg} / \mathrm{m}^{2} / \text { day, days } 1-4\end{array}$ & 1 & 4.2 \\
\hline Retinoblastoma & CTV & $\begin{array}{l}\mathrm{Ca}, 560 \mathrm{mg} / \mathrm{m}^{2} / \text { day, day } 1 \\
\mathrm{~T}, 200 \mathrm{mg} / \mathrm{m}^{2} / \text { day, day } 2 \\
\mathrm{~V}, 1.5 \mathrm{mg} / \mathrm{m}^{2} / \text { day, day } 2\end{array}$ & 5 & 100.0 \\
\hline \multirow[t]{2}{*}{ Rhabdomysarcoma } & DEV & $\begin{array}{l}\mathrm{D}, 450 \mu \mathrm{g} / \mathrm{m}^{2} / \text { day, days } 2-6 \\
\mathrm{E}, 100 \mathrm{mg} / \mathrm{m}^{2} / \text { day, days } 2-4 \\
\mathrm{~V}, 1.5 \mathrm{mg} / \mathrm{m}^{2} / \text { day, days } 1-8\end{array}$ & 1 & 25.0 \\
\hline & IEV & $\begin{array}{l}\mathrm{I}, 1.5 \mathrm{mg} / \mathrm{m}^{2} / \text { day, days } 2-6 \\
\mathrm{E}, 100 \mathrm{mg} / \mathrm{m}^{2} / \text { day, days } 2-6 \\
\mathrm{~V}, 1.5 \mathrm{mg} / \mathrm{m}^{2} / \text { day, days } 1-8\end{array}$ & 3 & 75.0 \\
\hline $\begin{array}{l}\text { Primitive neuroectodermal } \\
\text { tumor }\end{array}$ & $\mathrm{CDV}$ & $\begin{array}{l}\mathrm{Cy}, 2.1 \mathrm{~g} / \mathrm{m}^{2} / \text { day, days } 1-2 \\
\mathrm{D}, 25 \mathrm{mg} / \mathrm{m}^{2} / \text { day, days } 1-3 \\
\mathrm{~V}, 0.67 \mathrm{mg} / \mathrm{m}^{2} / \text { day, days } 1-3\end{array}$ & 2 & 100.0 \\
\hline Malignant schwannoma & $\mathrm{CDV}$ & $\begin{array}{l}\mathrm{Cy}, 2.1 \mathrm{~g} / \mathrm{m}^{2} / \text { day, days } 1-2 \\
\mathrm{D}, 25 \mathrm{mg} / \mathrm{m}^{2} / \text { day, days } 1-3 \\
\mathrm{~V}, 0.67 \mathrm{mg} / \mathrm{m}^{2} / \text { day, days } 1-3\end{array}$ & 1 & 100.0 \\
\hline Hepatoblastoma & $\mathrm{ACP}$ & $\begin{array}{l}\mathrm{A}, 25 \mathrm{mg} / \mathrm{m}^{2} / \text { day, days } 1-3 \\
\mathrm{Cy}, 0.8-1 \mathrm{~g} / \mathrm{m}^{2} / \text { day, day } 1 \\
\mathrm{P}, 20 \mathrm{mg} / \mathrm{m}^{2} / \text { day, days } 1-5\end{array}$ & 1 & 100.0 \\
\hline Wilms' tumor & DVA & $\begin{array}{l}\mathrm{D}, 15 \mu \mathrm{g} / \mathrm{m}^{2} / \text { day, days } 1-5 \\
\mathrm{~V}, 1.5 \mathrm{mg} / \mathrm{m}^{2} / \text { day, days } 1-8 \\
\mathrm{~A}, 20 \mathrm{mg} / \mathrm{m}^{2} / \text { day, days } 1-2\end{array}$ & 1 & 100.0 \\
\hline
\end{tabular}

A, aclacinomycin; Cy, cyclophosphamide; Ci, cisplatin; Ca, carboplatin; Dc, dactinomycin; Da*, daunorubicin; E, etoposide; I, ifosfamide; $\mathrm{P}$, paclitaxel; $\mathrm{T}$, teniposide; $\mathrm{V}$, vincristine.

Acute toxicity following reinfusion (on days $0,7,14,21$ and 28 post-transplantation) was defined according to the criteria proposed by Bearman et al (17). Lung function was observed after 30 days, and the viscera could be assessed after 60 days. A review was performed after every three months.

The prognosis of the children in this study was categorized according to integrated efficacy standards (18) as follows: i) $\mathrm{CR}$, the tumor disappeared completely following the treatment and no evidence of tumor residue was observed in the imaging examination; ii) PR, the tumor shrank by $>50 \%$ and no new lesions were observed; iii) PD, the tumor volume increased by $>25 \%$ and new tumor lesions appeared during the treatment; and iv) mortality.

During follow-up, the general situation, physical examination, onset site imaging, and analysis of the blood, bone marrow and associated tumor markers, were performed monthly for three months post-transplantation and then every third month of the first year, followed by every six months thereafter until five years post-transplantation.

Statistical analysis. SPSS software version 17.0 (SPSS, Inc., Chicago, IL, USA) was used for data analysis. All data were expressed as the mean \pm standard deviation, median (range) or $\mathrm{n}(\%)$, as appropriate. Fisher's exact test or the $\chi^{2}$ test were used to examine the association between qualitative variables. Survival and event-free curves were determined by the Kaplan-Meier method. $\mathrm{P}<0.05$ was considered to indicate a statistically significant difference.

\section{Results}

APBSC collection data. The mean number of collected MNCs and the CD34+ cell count from the 38 patients was $5.6 \pm 2.2 \times 10^{8} / \mathrm{kg}$ and $3.8 \pm 2.6 \times 10^{6} / \mathrm{kg}$, respectively. Of these 
Table III. Association between age and cycles chemotherapy, and the amount of stem cells obtained.

\begin{tabular}{lcccc}
\hline Variable & Cases, $\mathrm{n}$ & Collections, $\mathrm{n}(\mathrm{mean} \pm \mathrm{SD})$ & $\mathrm{MNC}\left(1 \times 10^{8} / \mathrm{kg}\right)$ & $\mathrm{CD} 34^{+}\left(1 \times 10^{6} / \mathrm{kg}\right)$ \\
\hline Age, years & & & & \\
$\quad \leq 5$ & 15 & $1.7 \pm 0.7$ & $6.3 \pm 2.2$ & $6.2 \pm 4.1$ \\
$>5$ & 23 & $2.6 \pm 0.9$ & $5.7 \pm 2.2$ & 0.417 \\
P-value & & 0.004 & & 0.004 \\
Cycles of chemotherapy & & & $6.0 \pm 2.0$ & $5.2 \pm 3.9$ \\
$\leq 10$ & 23 & & $5.8 \pm 2.5$ & $2.9 \pm 2.2$ \\
$>10$ & 15 & & 0.792 & 0.042 \\
P-value & & & \\
\hline
\end{tabular}

MNC, mononuclear cells.

Table IV. Toxicity and adverse reactions during the process of autologous peripheral blood stem cell reinfusion.

\begin{tabular}{lcc}
\hline Toxic reaction & Cases, $\mathrm{n}$ & Occurrence rate, $\%$ \\
\hline Hemoglobinuria & 38 & 100 \\
Hypertension & 18 & 47.4 \\
Nausea, vomiting & 16 & 42.1 \\
Abdominal pain & 9 & 23.7 \\
Arrhythmia & 8 & 21.1 \\
Headache & 8 & 21.1 \\
Hypoxemia & 7 & 18.4 \\
Fever & 5 & 13.2 \\
Diarrhea & 4 & 10.5 \\
\hline
\end{tabular}

38 patients, the number of stem cells collected from 31 cases $(81.6 \%)$ accorded with the transplantation standards (Table III).

The amount of $\mathrm{CD}_{3} 4^{+}$stem cells and the collection time were statistically different $(\mathrm{P}<0.05)$ between the two groups of children aged $>5$ and $\leq 5$ years, showing that children $<5$ years of age can contribute to the collection and acquisition of stem cells. No significant difference with respect to the amount of MNCs was observed between the two groups.

The amount of $\mathrm{CD}_{3} 4^{+}$cells in the patients receiving $<10$ chemotherapy cycles was significantly higher in comparison to those receiving $>10$ cycles $(\mathrm{P}<0.05$; Table III), suggesting that a greater number of chemotherapy cycles is detrimental to the acquisition of $\mathrm{CD} 34^{+}$cells.

Toxicity and adverse reactions of stem cell collection and reinfusion. All 38 patients developed class 2 or 3 gastrointestinal reactions and class 3 hair loss following chemotherapy. No hypotension, paleness, sweating, nausea, vomiting, numbness or chills were observed in the process of stem cell collection. Of the 38 cases, 32 patients displayed an increased heart rate and sinus tachycardia. The average amount of PLT loss was $48 \%$ (range, 30-55\%). Irradiated PLTs were administered into eight patients due to excessive stem cell collection.

All 38 patients developed hemoglobinuria on the day of reinfusion, and recovered within $12 \mathrm{~h}$ following hydration and
Table V. Distribution of organ toxicity in 37 surviving patients.

\begin{tabular}{lrrrrr}
\hline & \multicolumn{5}{c}{ Stage, $\mathrm{n}$} \\
\cline { 2 - 6 } Organ & \multicolumn{1}{c}{0} & I & II & III & IV \\
\hline Heart & 31 & 2 & 2 & 1 & 1 \\
Bladder & 36 & 1 & 0 & 0 & 0 \\
Kidney & 37 & 0 & 0 & 0 & 0 \\
Liver & 21 & 13 & 3 & 0 & 0 \\
Central nervous & 37 & 0 & 0 & 0 & 0 \\
system & & & & & \\
Oral & 12 & 13 & 7 & 4 & 1 \\
Gastrointestinal & 12 & 15 & 7 & 2 & 1 \\
Infection & 1 & 9 & 10 & 15 & 2 \\
Lung & 37 & 0 & 0 & 0 & 0 \\
\hline
\end{tabular}

urine alkalization. The detailed data is presented in Table IV. Oxygen saturation was within the normal range during reinfusion. Prior to intervention, the number of patients who developed grade $0-1$, grade 2 and grade $3-4$ adverse reactions was 5, 14 and 19, respectively, whereas 36, 2 and 0 patients, respectively, developed these adverse reactions following intervention $(\mathrm{P}<0.001)$. All adverse reactions were restored to normal within $24 \mathrm{~h}$ of symptomatic treatment.

Toxicity and adverse reactions during the process of bone marrow suppression following reinfusion. Three and 14 days after pretreatment in the 38 cases, there were 19 cases of grade I, 11 cases of grade II, five cases of grade III and three cases of grade IV adverse reaction. One patient with NB succumbed on the day 4 following HDCT during the process of bone marrow suppression, due to multiple organ failure and primary cardiac damage with low immune tolerance. According to Bearman's criteria, the toxicity and adverse reactions in the organs of the remaining 37 cases were summarized and are presented in Table V.

All 37 cases developed different degrees of oral ulceration, vomiting, diarrhea and plasma imbalance, which were gradually restored to normal on the 22 nd day after mucosal damage. 


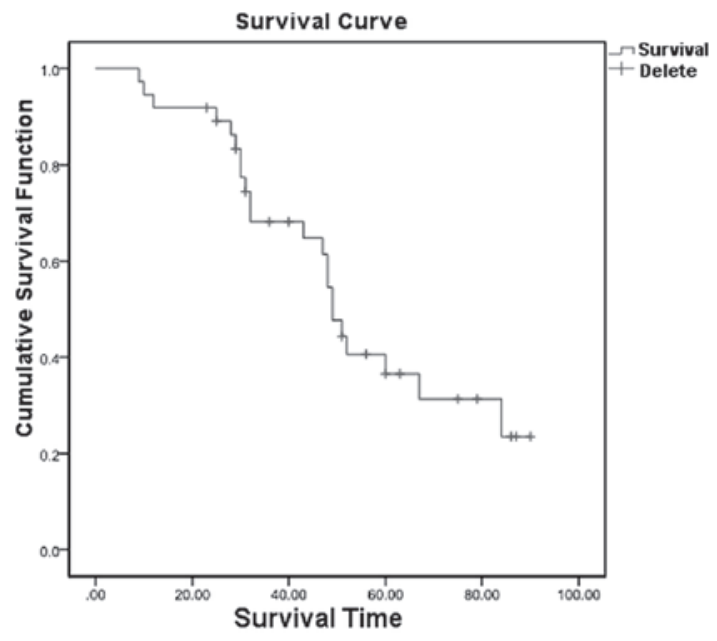

Figure 1. Cumulative survival curve of 37 cases. Kaplan-Meier analysis revealed that the one, three and five-year survival rates after APBSCT treatment were $91.9,68.2$ and $36.6 \%$, respectively.

There were four cases of sepsis, 19 of respiratory infections, eight of gastrointestinal infections, 3 of urinary tract infections and four of an unknown fever. All the diseases or associated clinical symptoms were controlled using broad-spectrum antibiotics. Of these 37 cases, one patient developed hypovolemic shock due to gastrointestinal bleeding caused by intestinal mucosal damage following chemotherapy, and recovered by symptomatic treatment within 22 days. Five cases presented with myocardial damage, arrhythmia and cardiac dysfunction due to HDCT (manifested as elevated creatine kinase-MB), but recovered within 60 days following cardiac treatment. Another 17 cases exhibited elevated levels of liver transaminases and three cases developed jaundice; these patients recovered following triple protection and symptomatic treatment for one week. One case whose mucosal was damaged by melphalan developed hemorrhagic cystitis, but recovered within one month following hydration and urine alkalization.

Efficacy and prognosis of APBSCs. The average time for bone marrow reconstitution in the 37 cases was $12.3 \pm 3.1$ days after reinfusion. The quantity of reinfused $\mathrm{CD} 34^{+}$cells was negatively correlated with the reconstitution time of the bone marrow ( $\mathrm{rs}=-0.634 ; \mathrm{P}=0.001$ ), showing that a high level of $\mathrm{CD} 34^{+}$cell collection can contribute to bone marrow reconstitution.

Subsequent to APBSCT treatment, the cumulative survival rates of the 37 patients at one, three and five years were $91.9,68.2$ and $36.6 \%$, respectively (95\% confidence interval, 44.89-53.11) (Fig. 1). Next, the 37 patients were subdivided into three groups, as follows: The $\mathrm{CR}$ group (13 cases), the PR group (14 cases) and the PD group (10 cases). The survival rates at 5 years post-treatment were $75.0 \%$ in the CR group, $36.5 \%$ in the PR group and $9.1 \%$ in the PD group (Fig. 2).

\section{Discussion}

With the widespread use of chemotherapy, surgery, radiation and biological immunotherapy, the survival rates of children

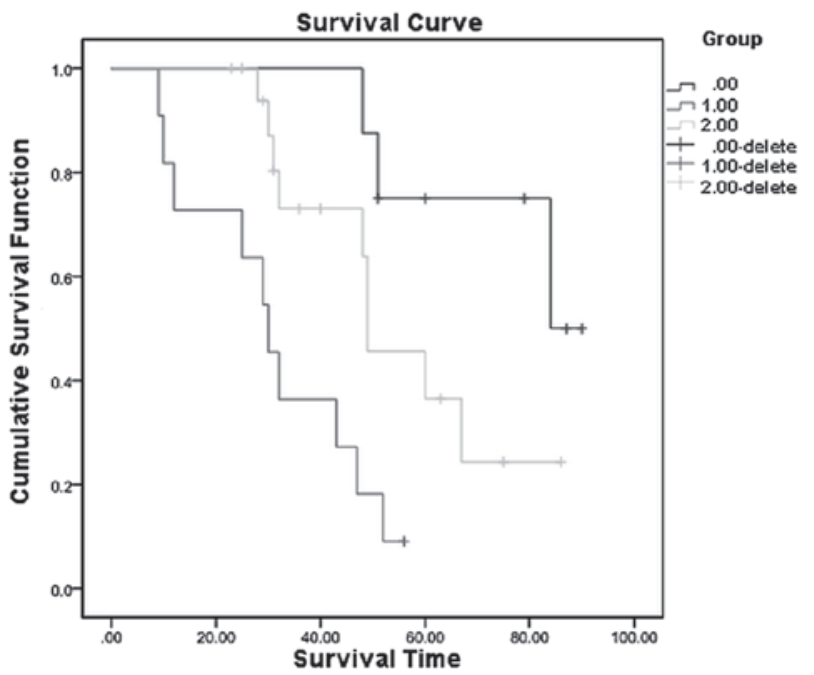

Figure 2. Cumulative survival curve of 37 cases divided into complete remission (CR), partial remission (PR) and progressive disease (PD) groups. The five-year survival rates were $75,36.5$ and $9.1 \%$ for the CR, PR and PD groups, respectively.

with advanced malignant solid tumors has improved significantly (19-21). However, due to the short incubation period, rapid growth and distant metastasis, regular treatment of advanced solid tumors only improves short-term survival, and rarely improves long-term survival (22-24). APBSCT was introduced into the clinic in 1985 and confers certain advantages, including rapid engraftment, rapid and complete hematopoietic reconstitution, a low risk of recurrence, fewer transplant-related complications, high safety and a low cost. Currently, APBSCT is one of the most effective methods for prolonging the lifespans of patients with malignant solid tumors, particularly advanced solid tumors $(25,26)$.

In the present study, the median survival time of the children was 49.0 months. The survival rate at one, three and five years post-treatment was $91.9,68.2$ and $36.6 \%$, respectively. These findings were consistent with the results of a previous study by Kushner et al (26). However, for the 10 cases with PD, the five year survival rate was only 9.1\%. Although APBSCT cannot alter the prognosis, it can prolong the survival time and reduce the tumor burden of PD in an individual patient. The present findings also indicated that children who were $<5$ years of age and underwent fewer chemotherapy cycles contribute to the collection and acquisition of stem cells. In addition, the long-term prognosis of CR and PR patients was also excellent, suggesting that powerful induction therapy in the early stages can contribute to $\mathrm{CR}$.

For children with malignant solid tumors, the method for controlling the risk during the mobilization, collection and reinfusion processes, and a reduction in the possibility of failing to receive APBSCT is important for increasing the success rate of the treatment and prolonging survival (27-29). In this study, the ABPSCTs of 38 patients were successfully mobilized, collected and reinfused, and engraftment and hematopoietic reconstitution was achieved following pre-transplant conditioning in all patients, with the exception of one, who succumbed to multiple organ failure. Additionally, it was demonstrated that the processed blood volume 
was positively associated with the $\mathrm{CD} 34^{+}$cell count in PBSC collection and the age of the children, which was in accordance with a previous study by Sevilla et al (30). Sufficient MNC and CD34 ${ }^{+}$cell counts were obtained from 31 of the 38 cases for PBSCT. During the process of PBSC collection, the children exhibited a low blood volume, resulting in vasovagal reactions, such as hypotension, tachycardia, paleness and severely hypovolemic shock. Therefore, continuous electrocardiogram and blood pressure monitoring in the process of PBSC collection contributes to the early detection of vasovagal reactions. Eight cases in the present study sustained a $48 \%$ rate of PLT loss following PBSC collection, and the corresponding measure was a timely intravenous infusion of PLTs.

According to the standards set in the study by Balduzzi et al (31), 31 cases $(81.6 \%)$ in the present study reached the required threshold value of stem cell transplantation. The remaining seven cases were all from patients with PD, which accounted for 70\% (7/10) of the total patients with PD, suggesting that the quantity of obtained stem cells was closely associated with the condition of the patient. An explanation for these findings is that patients with PD generally have a poorer physical condition, tolerance and hematopoietic bone marrow function following radiotherapy, chemotherapy and surgery, which leads to a decrease in the stem cell counts in comparison to patients in the remission stage.

Previous studies have shown that the occurrence of hemoglobinuria during the process of reinfusion is associated with erythrocyte lysis and the use of dimethyl sulfoxide in cryopreserved and thawed peripheral blood stem cell autografts $(32,33)$. In the present study, the incidence of acute renal dysfunction was reduced through a series of methods, including the use of hormones, hydration, alkalization and diuretic measures to ensure restoration to normal within 12 hours. In addition, it was found that 37 out of the 38 children developed severe infections, which may have been due to neutropenia and pretreatment in the bone marrow suppression and function recovery stages during the process of transplantation, thus conferring an increased risk of associated infection $(34,35)$. In the present study, the joint use of broad-spectrum antibiotic drugs played an important role in preventing and controlling infection from pediatric APBSCT.

In summary, the present study has demonstrated the safety and efficacy of HDCT followed by APBSCT for the treatment of children with advanced malignant solid tumors and suggests that HDCT with APBSCT may be used as a post-remission therapy. A prospective study will be necessary to analyze whether HDCT with auto-PBSCT will affect outcomes in the treatment of children with advanced malignant solid tumors.

\section{Acknowledgements}

This study was supported by a branch project of the Capital Characteristic Clinical Project from the Beijing Science and Technology Commission in China (grant no. Z121107001012057).

\section{References}

1. Shi X, Tian L, Zhu XD, Wang HM and Qin H: Effect of Chinese drugs combining with chemotherapy on quality of life in 146 children with solid tumor. Chin J Integr Med 17: 31-34, 2011
2. Müller HL, Oh Y, Lehrnbecher T, Blum WF and Rosenfeld RG: Insulin-like growth factor-binding protein-2 concentrations in cerebrospinal fluid and serum of children with malignant solid tumors or acute leukemia. J Clin Endocrinol Metab 79: 428-434, 1994.

3. Duan W, Jin X, Xiu Y, et al: Expression of the novel all-trans retinoic acid-related resistance gene HA117 in pediatric solid tumors. J Pediatr Hematol Oncol 36: 45-50, 2014.

4. Körbling $M$ and Freireich EJ: Twenty-five years of peripheral blood stem cell transplantation. Blood 117: 6411-6416, 2011.

5. Sheridan WP, Morstyn G, Wolf M, et al: Granulocyte colony-stimulating factor and neutrophil recovery after high-dose chemotherapy and autologous bone marrow transplantation. Lancet 2: 891-895, 1989.

6. Nademanee A, Sniecinski I, Schmidt GM, et al: High-dose therapy followed by autologous peripheral-blood stem-cell transplantation for patients with Hodgkin's disease and non-Hodgkin's lymphoma using unprimed and granulocyte colony-stimulating factormobilized peripheral-blood stem cells. J Clin Oncol 12: 2176-2186, 1994.

7. Bensinger WI, Clift R, Martin P, et al: Allogeneic peripheral blood stem cell transplantation in patients with advanced hematologic malignancies: a retrospective comparison with marrow transplantation. Blood 88: 2794-2800, 1996.

8. Körbling M, Fliedner TM, Holle R, et al: Autologous blood stem cell (ABSCT) versus purged bone marrow transplantation (pABMT) in standard risk AML: influence of source and cell composition of the autograft on hemopoietic reconstitution and disease-free survival. Bone Marrow Transplant 7: 343-349, 1991.

9. Mehta J, Powles R, Singhal S and Treleaven J: Peripheral blood stem cell transplantation may result in increased relapse of acute myeloid leukaemia due to reinfusion of a higher number of malignant cells. Bone Marrow Transplant 15: 652-653, 1995.

10. Reiffers J, Korbling M, Labopin M, Henon P and Gorin NC: Autologous blood stem cell transplantation versus autologous bone marrow transplantation for acute myeloid leukemia in first complete remission. Int J Cell Cloning 10 (Suppl S1): 111-113, 1992.

11. Demirer T, Petersen FB, Bensinger WI, et al: Autologous transplantation with peripheral blood stem cells collected after granulocyte colony-stimulating factor in patients with acute myelogenous leukemia. Bone Marrow Transplant 18: 29-34, 1996.

12. Gignac GA and Wexler LH: Effects of therapy for solid tumors. In: Fertility Preservation in Male Cancer Patients. Mulhall JP (ed). Cambridge University Press, Cambridge, pp119-128, 2013.

13. Taurin S and Greish K: Enhanced vascular permeability in solid tumors: a promise for anticancer nanomedicine. In: Tight Junctions in Cancer Metastasis. Martin TA and Jiang WG (eds). Springer, Dordrecht, pp81-118, 2013

14. Cesaro S, Nesi F, Tridello G, et al: A randomized, non-inferiority study comparing efficacy and safety of a single dose of pegfilgrastim versus daily filgrastim in pediatric patients after autologous peripheral blood stem cell transplant. PloS One 8: e53252, 2013.

15. Eto T, Takase K, Miyamoto T, et al: Autologous peripheral blood stem cell transplantation with granulocyte colony-stimulating factor combined conditioning regimen as a postremission therapy for acute myelogenous leukemia in first complete remission. Int J Hematol 98: 186-196, 2013.

16. Pulsipher MA, Chitphakdithai P, Logan BR, et al: Acute toxicities of unrelated bone marrow versus peripheral blood stem cell donation: results of a prospective trial from the National Marrow Donor Program. Blood 121: 197-206, 2013.

17. Bearman SI, Appelbaum FR, Buckner CD, et al: Regimen-related toxicity in patients undergoing bone marrow transplantation. J Clin Oncol 6: 1562-1568, 1988.

18. Corrias MV, Haupt R, Carlini B, et al: Peripheral blood stem cell tumor cell contamination and survival of neuroblastoma patients. Clin Cancer Res 12: 5680-5685, 2006.

19. Therasse P, Arbuck SG, Eisenhauer EA, et al: New guidelines to evaluate the response to treatment in solid tumors. European Organization for Research and Treatment of Cancer, National Cancer Institute of the United States, National Cancer Institute of Canada. J Natl Cancer Inst 92: 205-216, 2000.

20. Widemann BC, Salzer WL, Arceci RJ, et al: Phase I trial and pharmacokinetic study of the farnesyltransferase inhibitor tipifarnib in children with refractory solid tumors or neurofibromatosis type I and plexiform neurofibromas. J Clin Oncol 24: 507-516, 2006

21. Crist WM and Kun LE: Common solid tumors of childhood. N Engl J Med 324: 461-471, 1991. 
22. Hartmann O, Benhamou E, Beaujean F, et al: High-dose busulfan and cyclophosphamide with autologous bone marrow transplantation support in advanced malignancies in children: a phase II study. J Clin Oncol 4: 1804-1810, 1986.

23. Green DM, Kun LE, Matthay KK, et al: Relevance of historical therapeutic approaches to the contemporary treatment of pediatric solid tumors. Pediatr Blood Cancer 60: 1083-1094, 2013.

24. Macy ME, Duncan T, Whitlock J, et al: A multi-center phase Ib study of oxaliplatin (NSC\#266046) in combination with fluorouracil and leucovorin in pediatric patients with advanced solid tumors. Pediatr Blood Cancer 60: 230-236, 2013.

25. Kwon SY, Won SC, Han JW, Shin YJ and Lyu CJ: Feasibility of sequential high-dose chemotherapy in advanced pediatric solid tumors. Pediatr Hematol Oncol 27: 1-12, 2010.

26. Kushner BH, Kramer K, Meyers PA, Wollner N and Cheung NK: Pilot study of topotecan and high-dose cyclophosphamide for resistant pediatric solid tumors. Med Pediatr Oncol 35: 468-474, 2000 .

27. Hoffman JA, Shah AJ, Ross LA and Kapoor N: Adenoviral infections and a prospective trial of cidofovir in pediatric hematopoietic stem cell transplantation. Biol Blood Marrow Transplant 7: 388-394, 2001.

28. Ljungman P, Deliliers GL, Platzbecker U, et al: Cidofovir for cytomegalovirus infection and disease in allogeneic stem cell transplant recipients. The Infectious Diseases Working Party of the European Group for Blood and Marrow Transplantation. Blood 97: 388-392, 2001.
29. Klein HG, Spahn DR and Carson JL: Red blood cell transfusion in clinical practice. Lancet 370: 415-426, 2007.

30. Sevilla J, González-Vicent M, Madero L, García-Sánchez F and Angel Diaz M: Large volume leukapheresis in small children: safety profile and variables affecting peripheral blood progenitor cell collection. Bone Marrow Transplant 31: 263-267, 2003

31. Balduzzi A, Gooley T, Anasetti C, et al: Unrelated donor marrow transplantation in children. Blood 86: 3247-3256, 1995.

32. Okamoto Y, Takaue Y, Saito S, et al: Toxicities associated with cryopreserved and thawed peripheral blood stem cell autografts in children with active cancer. Transfusion 33: 578-581, 1993.

33. Attarian H, Feng Z, Buckner CD, MacLeod B and Rowley SD: Long-term cryopreservation of bone marrow for autologous transplantation. Bone Marrow Transplant 17: 425-430, 1996.

34. Wingard JR, Merz WG, Rinaldi MG, Johnson TR, Karp JE and Saral R: Increase in Candida krusei infection among patients with bone marrow transplantation and neutropenia treated prophylactically with fluconazole. N Engl J Med 325: 1274-1277, 1991

35. Howell A, Gumpel JM and Watts RW: Depression of bone marrow colony formation in gold-induced neutropenia. $\mathrm{Br}$ Med J 1: 432-434, 1975. 